\title{
TRANSFERENCIA DE EMBRIONES EN VACUNOS DE LECHE
}

El término "transferencia embrionaria", tomado literalmente, se refiere solamente a recoger un embrión de un animal donante y colocarlo en el oviducto o útero de una receptora.

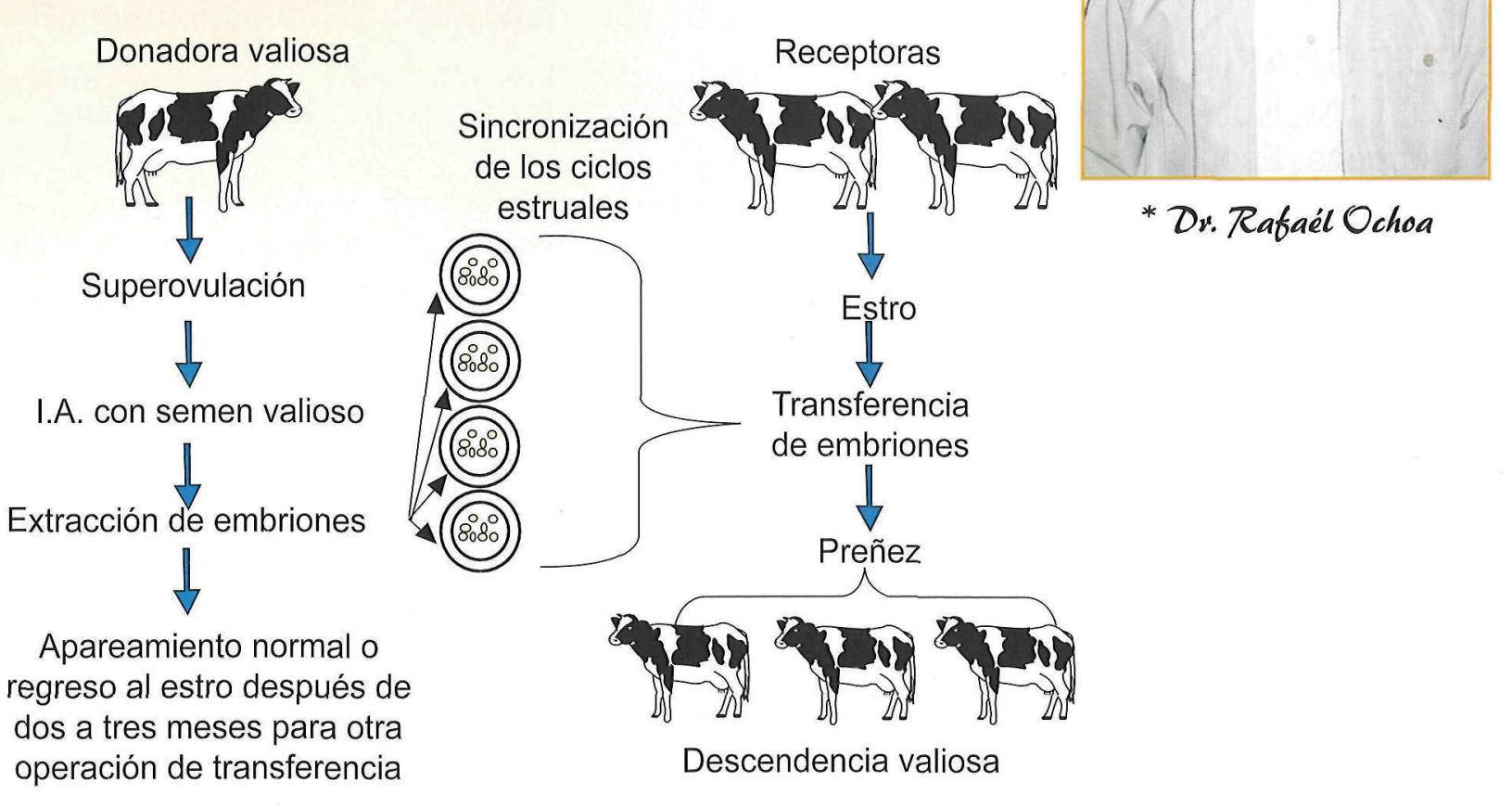

\section{Selección de las donantes}

Como donantes son válidas todas aquellas vacas adultas que no presentan ningún problema de tipo ginecológico. En última instancia se pueden incluir en la TE animales que poseen, como mínimo, las condiciones anatómico fisiológicas requeridas, esto es que se deben presentar ciclos regulares y posibilitar la palpación rectal. Especialmente aptos para ello son los animales que hayan parido de dos a tres veces, que hicieran celos regulares y que presenten un buen estado general. Como ejemplo podemos citar estos ejemplares aptos para ser donantes.

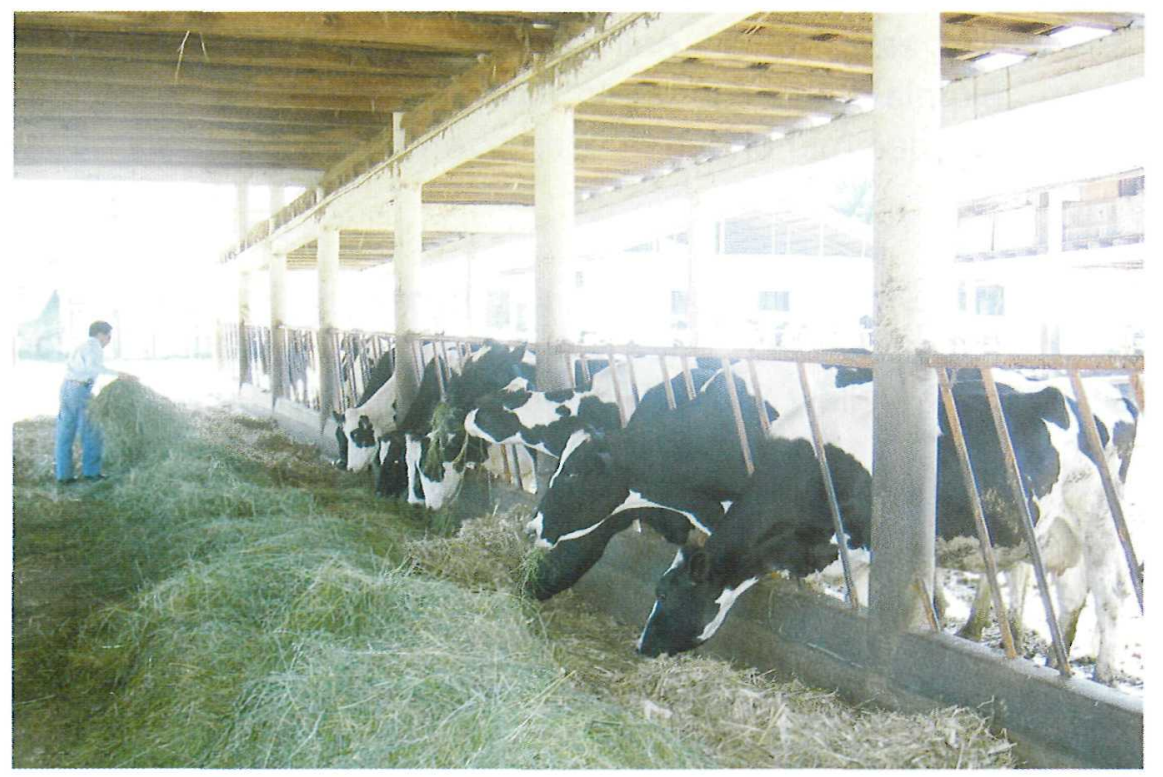




\section{Manejo y preparación}

Hay que tener en cuenta que se deben conservar los animales donantes en su ambiente normal, desde la inducción de la superovulación hasta el lavado y recogida de los embriones evitándose situaciones extraordinarias que desencadenen en estrés cuando participan en presentación a exposiciones y concursos.

\section{Sincronización previa}

Es indispensable confeccionar previamente un plan de sincronización, según el cual las hembras serán sincronizadas con una variación de +/- 3 días y los celos de las donantes a nuestra disposición deben de presentarse con una diferencia temporal de menos de 7 días entre ellos. Es aconsejable administrar HCG o GnRH durante el celo para inducir la ovulación y estabilizar el ciclo.

\section{Superovulación}

Consiste en la estimulación hormonal de la donante para la formación y desarrollo de varios folículos y su ovulación en ambos ovarios en un momento previamente fijado. La inducción de la superovulación se sucede en el diestro entre el día 8 y 14 del ciclo mediante la inyección de hormonas gonadotropinas como la FSH, PMSG o HCG. El celo súper ovulatorio se provoca finalmente con prostaglandina F2\%, la superovulación se puede inducir mediante la aplicación de una serie continuada de dosis decrecientes o iguales de FSH.

\section{Inseminación de las hembras donantes}

Debido a que las ovulaciones tienen lugar en momentos diferentes en un intervalo de tiempo amplio es necesario inseminar tres veces consecutivas cada 12 horas. Si la superovulación se ha inducido con FSH es conveniente aplicar en el momento de la segunda inseminación de 3000 a $5000 \mathrm{UI}$ de HCG para reducir algo el intervalo de tiempo en el que se suceden las ovulaciones.

\section{Animales receptores}

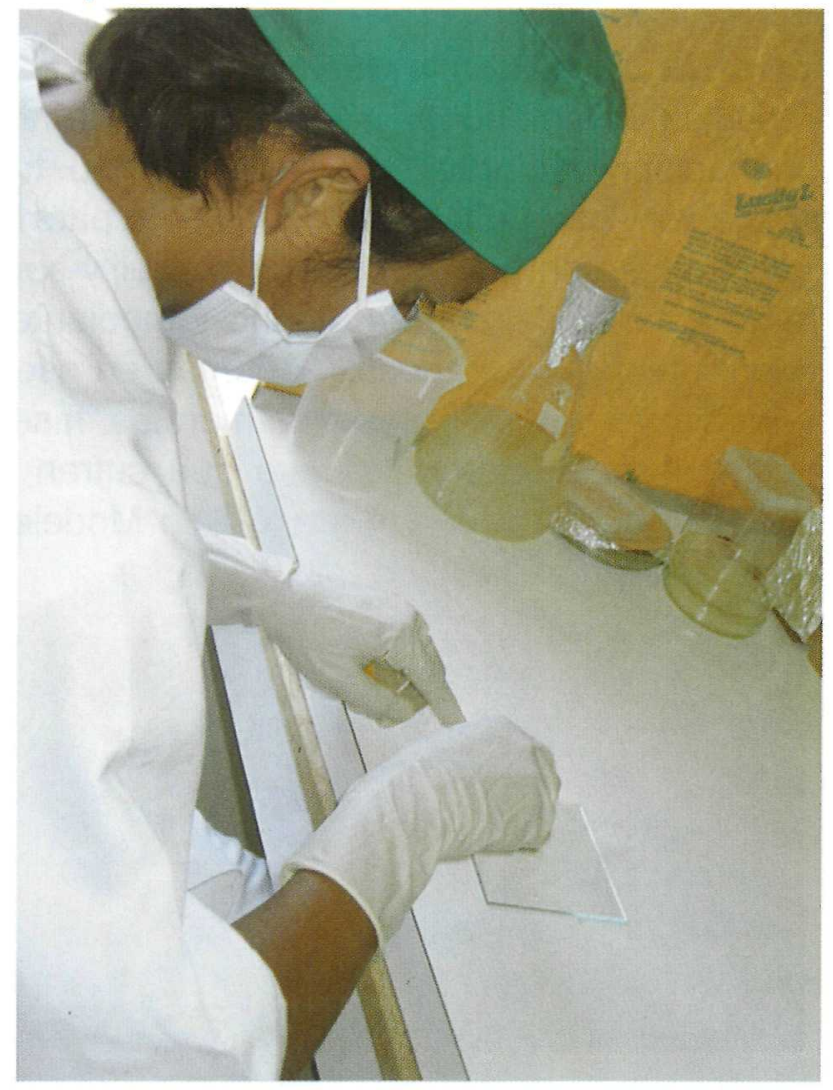

Toda novilla adulta, desde el punto de vista sexual y sin patologías reproductivas, así como toda vaca sana y sin trastornos ginecológicos, puede ser tomada como hembra receptora. La selección general desde el punto de vista genético en las receptoras no tiene mucho sentido, aun cuando no se puede descartar del todo una influencia materna de la receptora sobre los embriones y su desarrollo. 


\section{Sincronización del celo de las receptoras}

Se puede inducir o bien con progestágenos o con PGF2\%. Se le administra a las receptoras de 20 a 21 días antes de la transferencia la primera inyección de PGF2\% (presincronización) y el día $9^{\circ}$ antes de la TE se les administra la $2^{\circ}$ dosis de PGF2\%, junto con la donante (sincronización).

Un método de sincronización alternativo al anteriormente descrito consiste en administrar la PGF2\% a las receptoras 12 horas antes de aplicársela a las donantes.

Los animales receptores suelen presentar, por lo general, el celo inducido por PGF2\% algo más tarde que los tratados previamente con FSH o PMSG, lo que ayuda aún más a ajustar la sincronización entre donante y receptora.

El celo sincronizado, que será el día $6^{\circ}-7^{\circ}$ antes de la TE se puede administrar GnRH a las receptoras para estimular la ovulación y estabilizar el ciclo. Lo importante es que los animales muestren un celo patente en el momento adecuado, sincronizado con el de la donante y que en el momento de la transferencia presenten un cuerpo lúteo fácilmente palpable y bien estructurado.

\section{Recogida de embriones}

La recogida de embriones se realiza, preferentemente, el $7^{\circ}$ día después de la primera inseminación mediante un lavado uterino transcervical. El día $7^{0}$ tras la primera inseminación, es el día más conveniente para realizar el lavado puesto que es cuando los embriones son más fáciles de extraer y separar. En ese momento se ubican en el extremo anterior del cuerno uterino y mediante el lavado son fácilmente arrastrados al exterior flotando en el medio. Además en ese momento los embriones se encuentran en el estadio de blastocistos o de mórulas, fases muy estables, lo que hace posible que sean transferidos directamente o que sufran otras manipulaciones. A continuación podemos observar la sonda de lavado Modelo Neustadt/Aisch con el balón inflado, la jeringa de aire mosquito y mandril o fiador.

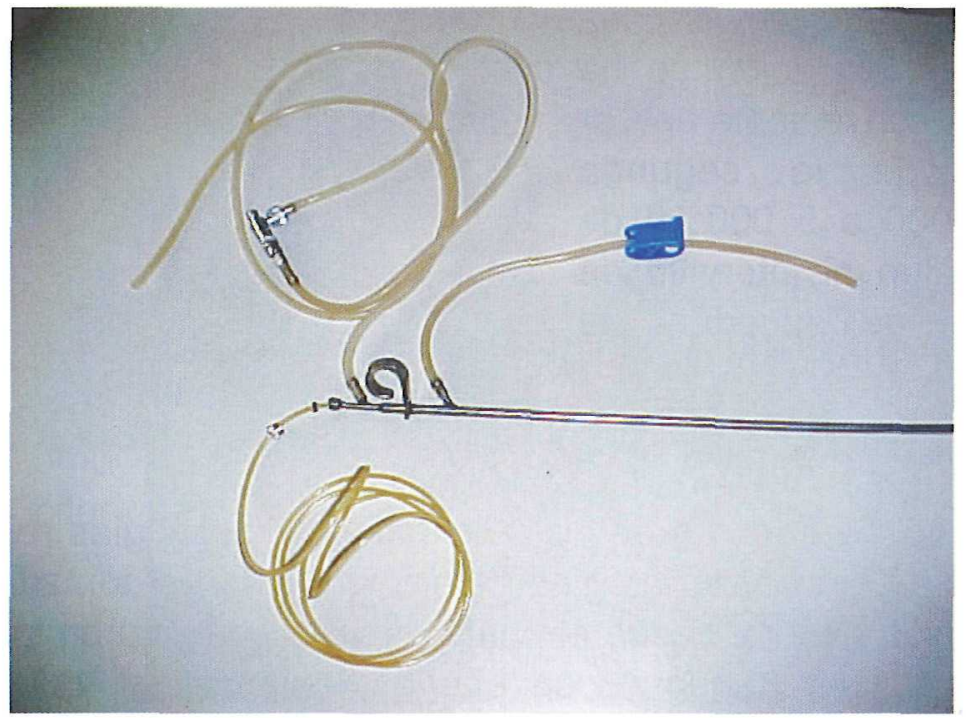




\section{Recogida de los embriones bajo control rectal manual}

El medio resultante de la recogida se mantiene a temperatura ambiente hasta el aislamiento de los embriones, debiéndose evitar oscilaciones de temperatura. El medio de lavado que refluye se recoge en un matraz o en una probeta o se conduce directamente a través de un filtro de embriones. La utilización del filtro de embriones integrado en el sistema optimiza el proceso, en la medida en que la solución de lavado es filtrada directamente y no es sistema cerrado es que ni la solución ni, por tanto, los embriones entran en contacto con el ambiente.

\section{Aislamiento de los embriones}

Los recipientes con la solución resultante del lavado de embriones se mantienen a temperatura ambiente hasta el aislamiento de los mismos. Aunque los embriones son relativamente resistentes a la temperatura en caso de una bajada de la misma, no se debe superar bajo ningún concepto una temperatura ambiente de menos de $20^{\circ} \mathrm{C}$. Para ello se vierte toda la solución exceptuando los últimos $50 \mathrm{ml}$, por un filtro de embriones o bien se aspira el sobrenadante después de que los embriones se hayan sedimentado. Dicha sedimentación dura entre unos 15 ó 20 minutos.

Se utiliza un filtro de embriones (con un tamaño de poro de $70 \mathrm{~mm}$ ), se vierte la solución de lavado directamente sobre el filtro, agitando simultánea y suavemente el recipiente hasta vaciarlo; con la agitación se pretende evitar que los embriones que hayan sedimentado permanezcan en el matraz. Mientras dure el filtrado, se debe procurar que los embriones retenidos por el filtro estén en todo momento rodeados de líquido puesto que, en caso contrario, se deshidratan.

\section{Valoración de los embriones}

Bajo la lupa estereoscópica con haz de luz difusa, entre 10 y 60 aumentos, se examina el estado morfológico de los embriones y se clasifican según su calidad. Los embriones en perfecto estado desde el punto de vista morfológico se pasan a una pequeña placa de Petri con medio de cultivo recién filtrado y así se lavan 10 veces (para diluir posibles gérmenes), conservándose a temperatura ambiente hasta su transferencia o próxima manipulación.

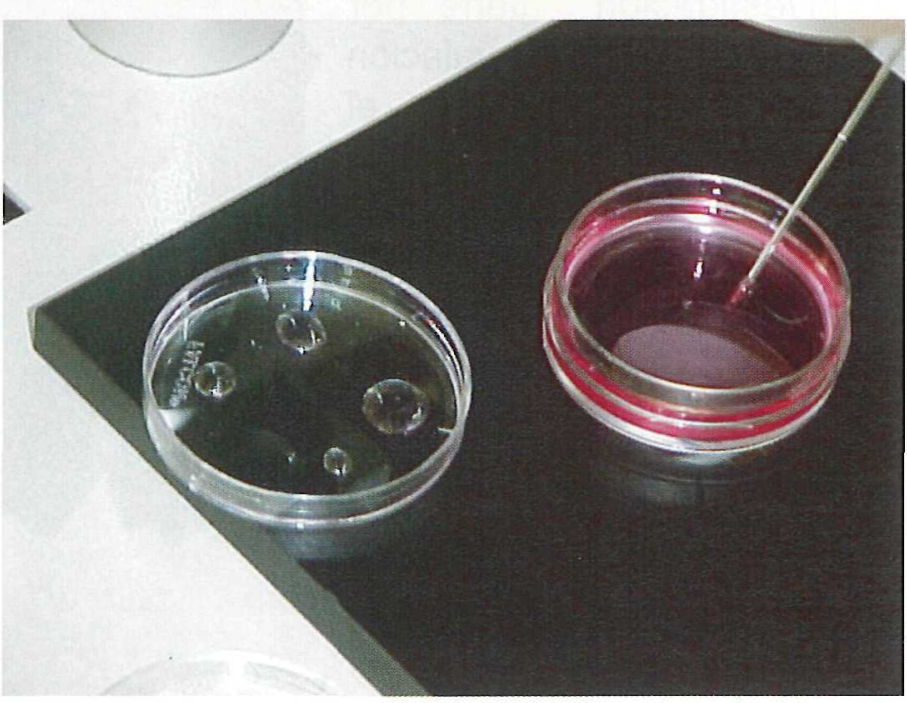

\section{Implatanción de los embriones}

La transferencia de los embriones se puede llevar a cabo de forma quirúrgica o no quirúrgica transcervical. Los embriones a transferir de las clases 1 hasta la 4 , preferiblemente hasta las clases 3. 


\section{Transferencia no quirúrgica transcervical}

Es actualmente el método de elección y se lleva a cabo al igual que la inseminación artificial, bajo la palpación rectal por las vías naturales a través de la vagina, cervix, cuerpo de la matriz hasta el cuerno uterino ipsilateral. Para ello se coloca el embrión ya localizado en la pajuela $(0.25 \mathrm{ml})$ en el catéter de transferencia cuya apertura se encuentra situada lateralmente en el extremo final del mismo.

En el momento en que el catéter se encuentre en la posición requerida se presiona el mandril depositando el embrión en el lumen uterino.

\section{Almacenamiento y conservación de los embriones}

Los embriones obtenidos tras el lavado se pueden manipular de diversas formas. Así pues, el mantenimiento de los embriones en medio del cultivo a temperatura ambiente es el modo más efectivo y fácil de superar un intervalo corto de tiempo (de varias horas) y de gran interés es la crío conservación en caso de tratarse de períodos de tiempo más extensos o de tener que salvarse distancias considerables (comercio de importación/exportación, escasez de receptoras, reserva genética, exámenes analíticos previos a la transferencia/tipicación del genoma, etc.).

La Facultad de Ciencias Agropecuarias y Ambientales conciente de la necesidad de impulsar proyectos de investigación en el área pecuaria estimó conveniente aprobar el tema de tesis de transferencia de embriones que se encuentra realizando el señor egresado Néstor Cárdenas Lennerth Loayza en la provincia de El Oro en el Cantón Piñas; dicha investigación tiene por objetivo realizar la superovulación con la finalidad de efectuar el lavado de embriones, utilizando la técnica no quirúrgica o transrectal de tres vacas de la raza Pardo Suiza y determinar el porcentaje de mayor receptibilidad en tres razas de receptoras como la Holstein Friesian, Pardo Suiza y Brahaman, tomado como factor de evaluación cinco receptoras de

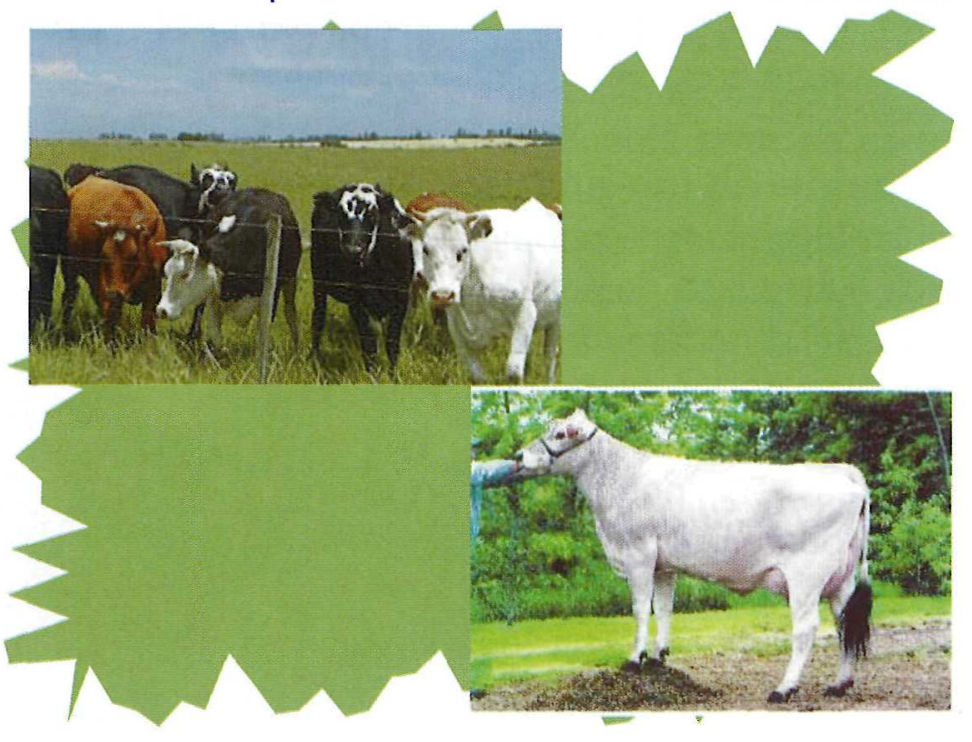
cada raza.

Aplicando de esta manera los conocimientos científicos y utilizando las herramientas genéticas acordes a las necesidades del nuevo milenio. 


\section{Extracción de los embriones}

La recogida no quirúrgica o lavado de los embriones se realiza a través de la vagina, bajo control rectal y con el animal en estación; tiene una duración de 15 a 20 minutos por animal y es sencillo y efectivo. Para el lavado se utiliza un catéter o sonda flexible con balón hinchable, que se introduce con un mandril o fiador, para hacerlo rígido, a través de la vagina, cervix y cuerpo uterino hasta uno de los cuernos. Cuando el extremo de la sonda se halla en la curvatura mayor del cuerno uterino se retira el mandril de 8 a $10 \mathrm{~cm}$ y se sigue avanzando con cuidado con la sonda flexible en dirección craneal. A continuación se infla el balón que se encuentra inmediatamente detrás del extremo del catéter (de 10 a $20 \mathrm{ml}$ ).

Se controla el grosor y la situación del balón y se retira el fiador totalmente. La situación del catéter es correcta cuando el balón, según los diferentes tamaños de los distintos úteros, se encuentra a más o menos $5 \mathrm{~cm}$ craneal a la bifurcación uterina, a la altura aproximadamente del ligamento intercornual.

La recogida de los embriones se lleva a cabo por medio de un lavado con una solución templada en fracciones de $(30$ a $50 \mathrm{ml})$ que fluyen de nuevo al matraz de recogida previamente tratado con silicona, tras retirar la jeringuilla de la sonda; es conveniente mover y masajear ligeramente el cuerno uterino. Así, los embriones localizados en criptas o pliegues son arrastrados por la corriente del medio hacia el exterior; al finalizar el lavado de uno de los cuernos uterinos se debe infundir de nuevo de 20 a $50 \mathrm{ml}$ de medio levantándose el extremo craneal del cuerno para posibilitar el reflujo del último resto de líquido infundido ahí acumulado.

\section{* Catedrático de Reproducción Animal}

